\title{
RESEARCH
}

Open Access

\section{GSK3 $\beta$ rephosphorylation rescues ALPL deficiency-induced impairment of odontoblastic differentiation of DPSCs}

\author{
Liqiang Zhang ${ }^{1,2+}$, Jiangdong Zhao ${ }^{3+}$, Jiayi Dong ${ }^{4}$, Yuting Liu' ${ }^{1}$ Kun Xuan ${ }^{4,5^{*}}$ and Wenjia Liu ${ }^{1,2 *}$
}

\begin{abstract}
Background: Premature exfoliation of the deciduous teeth is a common manifestation in childhood patients with hypophosphatasia (HPP), which is an autosomal inherited disease caused by ALPL mutations. Dysplasia of the cementum, dentin, and alveolar bone has been proposed to be the main reasons for the exfoliation of teeth, while the extraordinarily complex intracellular mechanisms remain elusive. Dental pulp stem cells (DPSCs) have been demonstrated to successfully regenerate functional pulp-dentin-like tissue. Dental pulp cells derived from HPP patients impaired mineralization; however, insight into the deeper mechanism is still unclear.
\end{abstract}

Methods: The effects of ALPL on odontoblastic differentiation of DPSCs from HPP patient were assessed by Alizarin Red staining, immunofluorescent staining, Western blot and RT-PCR, and micro-CT assays.

Result: Here, we found DPSCs from HPP patient exhibited low ALP activity and impaired odontoblastic differentiation. Meanwhile, we found that loss of function of ALPL reduced phosphorylation of GSK3 $\beta$ in DPSCs. While GSK3 $\beta$ rephosphorylation improved odontoblastic differentiation of HPP DPSCs with LiCl treatment. Finally, we demonstrated systemic LiCl injection ameliorated tooth-associated defects in $\mathrm{ALPL}^{+/-}$mice by enhanced phosphorylation of GSK3 $\beta$ in the teeth.

Conclusions: Our study indicates that ALPL regulates odontoblastic differentiation of DPSCS and provides useful information for understanding how ALPL deficiency led to tooth dysplasia and, ultimately, may inform efforts at improvement tooth defects in HPP patients.

Keywords: Hypophosphatasia, Tooth defects, Odontoblastic differentiation, ALPL, DPSCs, GSK3 $\beta$

\footnotetext{
* Correspondence: xuankun@fmmu.edu.cn; wenjialiu@xjtu.edu.cn; wenjia@xiterm.com

${ }^{\dagger}$ Liqiang Zhang and Jiangdong Zhao contributed equally to this work.

${ }^{4}$ State Key Laboratory of Military Stomatology \& National Clinical Research Center for Oral Diseases \& Shaanxi International Joint Research Center for Oral Diseases, Center for Tissue Engineering, School of Stomatology, The Fourth Military Medical University, No. 145 West Changle Road, Xi'an 710032,

Shaanxi, China

'National \& Local Joint Engineering Research Center of Biodiagnosis and Biotherapy, Precision Medicine Institute, The Second Affiliated Hospital of Xi'an Jiaotong University, No.157 Xiwu Road, Xi'an 710004, China Full list of author information is available at the end of the article
} changes were made. The images or other third party material in this article are included in the article's Creative Commons licence, unless indicated otherwise in a credit line to the material. If material is not included in the article's Creative Commons licence and your intended use is not permitted by statutory regulation or exceeds the permitted use, you will need to obtain permission directly from the copyright holder. To view a copy of this licence, visit http://creativecommons.org/licenses/by/4.0/ The Creative Commons Public Domain Dedication waiver (http://creativecommons.org/publicdomain/zero/1.0/) applies to the data made available in this article, unless otherwise stated in a credit line to the data. 


\section{Background}

Hypophosphatasia (HPP) is an inherited disease characterized with insufficient mineralization of the teeth and skeletal system caused by gene mutations of liver/bone/ kidney-type alkaline phosphatase (ALPL), which encoded tissue-nonspecific alkaline phosphatase (TNAP) and leading to reduce activity of the enzyme [1-3]. The clinical manifestations of patients with HPP are a broad range from life-threatening in infantile or death in utero to mild forms in childhood or adult with only dental or skeletal symptoms. Accumulating clinical trials suggest that asfotase alfa $\left(\right.$ Strensiq $\left.{ }^{\mathrm{TM}}\right)$, a first-in-class drug was permitted to use for therapy for patients with HPP, and treatment can significantly improve the outcome for the life-threatened patients with HPP [4-6]. However, several problems remain to be worked out, despite asfotase alfa exhibited a significant improvement on bone mineralization. Hypersensitive and ectopic calcification in injection sites, pneumonia, and even severe chronic hepatitis or failed treatment have been reported [7-9], and the longer-time effects of asfotase alfa therapy in these HPP patients are still unknown.

Premature exfoliation of the deciduous teeth is the most common manifestation in childhood patients with HPP and severely affects the quality of life for the patients. Asfotase alfa on the improvement tooth defects in HPP patients was few reported. In addition, the expensive cost should also be considered, especially in economically under-developed areas. Thus, cheaper and more effective strategies need to be developed based on discovering molecular mechanism for treatment patients with HPP, especially in the mild forms of childhood- or odonto-HPP. Dysplasia or aplasia of the cementum, dentin, and alveolar bone was frequently observed in patients with HPP [10-12] and have been proposed to be the main reasons for the exfoliation of the teeth; however, the complex cellular mechanisms remain elusive.

Dental pulp stem cells (DPSCs) have been identified to be a population of capable of multilineage differentiation into a variety of cell types, including neurons, adipocytes, osteoblasts, and odontoblasts [13]. Strong evidences have demonstrated that DPSCs with tooth slice or root canal-scaffold could regenerate pulp-dentin like complex tissues when transplanted into subcutaneous of immunocompromised mice $[14,15]$. Notably, our previous work showed that implanted autologous DPSCs aggregates into necrotic immature permanent incisors of pediatric patients successfully regenerated functional dental pulp with odontoblast layer [16]. These evidences suggest that DPSCs display excellent regenerative ability, which is important for tooth development and regeneration. Despite some studies have showed that dental pulp cells derived from HPP patients reduced ALP activity and actually impaired mineralization [17, 18], insight into the deeper mechanism remains unclear.
Canonical Wnt/ß-catenin pathway is a key regulator for controlling mesenchymal stem cell (MSC) differentiation into osteoblasts/odontoblasts $[19,20]$. Previous studies demonstrated that $\mathrm{LiCl}$, an agonist of the canonical Wnt signaling by increased phosphorylation of GSK3 $\beta$ at Ser9 $[20,21]$, effectively stabilizes free cytosolic $\beta$-catenin leading to $\beta$-catenin translocation into nucleus. These reports showed that $\mathrm{LiCl}$ drives the transcription of target genes of canonical Wnt pathway, such as Runx 2 and ALPL, and thereby enhanced MSC differentiation into osteoblasts $[20,21]$. We have recently demonstrated that ALPL mutation impaired osteogenic differentiation of BMSCs due to impede activation of Wnt/ $\beta$-catenin pathway [22]. Summary, these studies largely implied that there is a feasible regulatory loop between ALPL and canonical Wnt pathways.

In this study, tooth defects were observed both in HPP patients and $\mathrm{ALPL}^{+/-}$mice. In addition, DPSCs from HPP patient (HPP DPSCs) displayed low ALP activity and impaired lineage differentiation into odontoblasts. Subsequently, we found that loss function of ALPL inhibited activation of canonical Wnt pathway. While reactivating of canonical Wnt pathway promoted odontoblastic differentiation of HPP DPSCs with $\mathrm{LiCl}$ treatment. Finally, we demonstrated systemic $\mathrm{LiCl}$ injection ameliorated insufficient mineralization of tooth and mandible bone, and also improved exposure of collagen fiber network on the surface of dentinal tubules in $\mathrm{ALPL}^{+/-}$mice. This work provides useful information for understanding tooth associated disorders caused by loss of function of ALPL and, ultimately, may inform efforts at improvement tooth defects in HPP patients.

\section{Methods \\ Animals}

Female $\mathrm{ALPL}^{+/}$mice (B6.129S7-Akp2tm1Sor/J, pure C57BL/6 J genetic background) were purchased from Jackson labs (Bar Harbor, USA) and maintained in specific pathogen-free conditions at $24{ }^{\circ} \mathrm{C}$ with a 12-h light/dark cycle. All of the procedures that involved animals were approved by the Animal Ethics Committee of the Xi'an Jiaotong University. Primers used for genotyping include: mutant-5' CCGTGCATCTGCCAGTTTGAGGGGA3', wild type-5'CTGGCACAAAAGAGTTGGTAAGGCAG3', common-5' GATCGGAACGTCAATTAACGTCAAT3'.

\section{Isolation and culture of DPSCs}

Tooth samples were collected from healthy teeth extracted for orthodontic reasons and one patient with HPP (Dental Clinic of the Fourth Military Medical University, Xi'an, China). The clinical study was approved by the Ethics Committee of the Stomatology Hospital of the Fourth Military Medical University, and written informed consent was obtained from all participants prior 
to use tooth samples. To isolate dental pulp stem cells (DPSCs), dental pulp was enzymatically digested with type I collagenase $(0.66 \mathrm{mg} / \mathrm{ml}$; Sigma, USA) for $30 \mathrm{~min}$, and single-cell deposits were suspended and cultured in a-MEM (Gibco, USA) supplemented with 10\% FBS, 2 $\mathrm{mM}$ L-glutamine (Invitrogen, USA), $100 \mathrm{U} / \mathrm{ml}$ penicillin and $100 \mathrm{mg} / \mathrm{ml}$ streptomycin (Gibco) at $37^{\circ} \mathrm{C}$ of $5 \%$ $\mathrm{CO}_{2}$.

\section{Alkaline phosphatase activity assay}

To analyze alkaline phosphatase activity, the total proteins of DPSCs from normal and HPP patient were isolated and examined using an alkaline phosphatase assay kit from NJJCBIO company (NJJCBIO, A059-2-2, China) according to the manufacturer's instructions. ALP activity was corrected with total proteins and ultimately was present as $\mathrm{U} / \mathrm{g}$.

\section{Colony-forming unit (CFU) assays}

To assess the capacity and efficiency of cell self-renewal, $3 \times 10^{3}$ DPSCs at passage 2 were seeded in a $5-\mathrm{cm}$ plastic dish with $3 \mathrm{~mL}$ complete medium, and the medium was refreshed every 3 days for 2 weeks. On day 14, cells were washed with PBS, fixed by $4 \%$ paraformaldehyde, and stained with $0.5 \%$ toluidine blue for $30 \mathrm{~min}$. Then, cells were washed with $\mathrm{ddH}_{2} \mathrm{O}$ until the dye stopped coming off. When a colony contains more than 50 cells were counted for one CFU, and the number of CFU in the dish was counted.

\section{Flow cytometry analysis}

For identification of DPSCs phenotype, $3 \times 10 \mathrm{E} 5$ DPSCs (passage 3) were incubated with PE- or FITC-conjugated monoclonal antibodies against human CD29, CD44, CD73, CD90, CD105, CD34, CD45 (eBioscience, CA), and Stro-1 (R\&D Systems, MN) (sFig. 1), and flow cytometric analysis were performed using a Beckman CytoFLEX S flow cytometer (Beckman Coulter, USA).

\section{Cell proliferation and apoptosis assay}

To analyze cell proliferation or cell apoptosis of DPSCs, cell cycle and apoptosis analysis were performed by flow cytometric analysis. For cell proliferation assays, DPSCs cultured in $25 \mathrm{~cm}^{2}$ culture flask with $0.1 \%$ a-MEM medium for $12 \mathrm{~h}$ and then replaced and cultured with $10 \%$ a-MEM medium for $24 \mathrm{~h}$. Subsequently, the cells were digested with $0.25 \%$ trypsin and collected, fixed in precooling $70 \%$ ethanol overnight at $4{ }^{\circ} \mathrm{C}$, and cell cycle tests were performed with a Cell Cycle and Apoptosis Analysis Kit (Yeasen, 40301ES60, China) according to the manufacture's instruction. For cell apoptosis assays, the cells were digested with $0.25 \%$ trypsin and collected, and cell apoptosis tests were performed with a Annexin
V-FITC/PI Apoptosis Detection Kit (Yeasen, 40302ES60, China) according to the manufacture's instruction.

\section{DPSCs induced odontoblastic differentiation}

DPSCs were incubated in odontoblastic medium $(100 \mathrm{nM}$ dexamethasone, $50 \mathrm{mg} / \mathrm{ml}$ ascorbic acid, and $5 \mathrm{mM} \beta$ glycerophosphate) for 3 weeks. To assess odontoblastic differentiation, the expression of DSPP and DMP1 were detected by real-time polymerase chain reaction (RTPCR) and Western blotting after induced in odontoblastic medium 1 week. To analyze the mineralized nodes, the cells were stained with $1 \%$ Alizarin Red (Sigma, USA) after induced in odontoblastic medium 3 weeks. The mineralized nodules were dissolved with cetylpyridinium chloride monohydrate, and quantitative parameters were measured by spectrophotometer at $570 \mathrm{~nm}$.

\section{Scan electron microscopy (SEM) assay}

The human teeth, or molars from wild-type or $\mathrm{ALPL}^{+/-}$ mice, were fixed in $2.5 \%$ glutaraldehyde overnight at $4{ }^{\circ} \mathrm{C}$, washed with $10 \%$ sodium hypochlorite in ultrasonic cleaning instrument for $30 \mathrm{~min}$. Then, the samples were dried, coated with gold, and were imaged with a scanning electron microscope (SEM, S-3400 N) at a voltage of $5.0 \mathrm{kV}$. All measurements were made using the Cell Sense morphometric program (Olympus).

\section{Real-time PCR (RT-PCR) analysis}

Total DPSC RNAs were isolated and extracted by RNAiso plus (TaKaRa, Japan) according to the manufacture's instruction. Then, the mRNA was reversely transcribed into cDNA by Primescript ${ }^{\text {tm }}$ RT master mix (TaKaRa, RR036A, Japan). Real-time PCR was performed with TB Green ${ }^{\circ}$ Premix Ex Taq ${ }^{\text {ma }}$ GC (TaKaRa, RR071A, Japan) and detected by CFX96 Trademark Real-time PCR detection system (Bio-rad, USA). Expression levels of DSPP, DMP1, and $\beta$-catenin were examined. All the RT-PCR data are presented as mean \pm s.d. for triplicate samples from a representative experiment $(n=3)$. The primers used in real-time PCR were listed in the supplementary Table 1.

\section{Western blotting analysis}

Total proteins from DPSCs were harvested with RIPA lysis buffer (Beyotime, China). The proteins were separated in sodium dodecyl sulfonate-polyacrylamide gels (SDS-PAGE), transferred to PVDF membranes (Millipore, USA), blocked in TBST containing 5\% BSA, and then incubated in first antibodies with ALPL (Abcam, ab108337, 1:1000), DSPP (Santa Cruz Biotechnology, sc73632, 1:500), DMP1 (Santa Cruz Biotechnology, sc6551, 1:500), total GSK3 $\beta$ (Cell signaling technology, 9832, 1:1000), p-GSK3 $\beta$ (cell signaling technology, 9323, 1:1000), $\beta$-catenin (cell signaling technology, 8480s, 1 : 
1000), active $\beta$-catenin (Millipore, 05-665, 1:1000), $\mathrm{p}$ AMPK (cell signaling technology, 2535, 1:1000), p-ERK (cell signaling technology, 9101s, 1:1000), Gli1 (Novus Biological, NBP1-78259), TGF $\beta$ (Santa Cruz Biotechnology, sc-398, 1:500), and GAPDH (Cwbiotech, CW0100, 1:4000), respectively. Next day, the membranes incubated in secondary antibodies coupled to peroxidase (Cwbiotech, China). Finally, the signals were detected by an enhanced chemiluminescence kit (7seapharmtech, China).

\section{Immunofluorescent staining}

For immunofluorescent staining, single mandibular hemi-sections were fixed in $4 \%$ paraformaldehyde overnight at $4{ }^{\circ} \mathrm{C}$, decalcified with $10 \%$ EDTA (pH 7.0) in shaking incubators. The decalcified solution was refreshed every day for 2 weeks. The samples were embedded in Optimal Cutting Temperature (OCT, Leica) and sectioned into $10-\mu \mathrm{m}$ sections. Then, the sections were washed with PBS, incubated with $0.03 \%$ triton- 100 for $10 \mathrm{~min}$ at room temperature, and blocked with PBS containing 1\% BSA for $30 \mathrm{~min}$ at room temperature. Then, the sections were incubated overnight with primary antibodies to p-GSK3 $\beta$ (1:100, Cell signaling technology, 9323), and active $\beta$-catenin (1:100, Millipore, 05$665)$ at $4{ }^{\circ} \mathrm{C}$ respectively, and subsequently incubated with fluorescent secondary antibodies $(1: 200)$ for $2 \mathrm{~h}$ at room temperature. The positive cells were examined under a laser scanning confocal microscope (Olympus FluoViem FV 1000, Tokyo, Japan).

\section{Micro-computed tomography analysis}

The micro-CT scans of single mandibular hemi-sections were performed at the molar level using a GE micro-CT system (GE, USA). X-ray source was set at $80 \mathrm{kV}$, and $80-\mu \mathrm{A}$ microfocus. Three-dimensional images were reconstructed, and data analysis was performed by GEHC MicroView analysis software. The single mandibular regions and sagittal planes were chosen for comparison.

\section{Lentiviral vector construction and transduction}

To upregulate ALPL, ALPL was amplified from cDNA of human SEHD by PCR. Then, the PCR product was digested with the restriction enzymes BamH I and Xho I and then inserted into the pLenti 6.3 vector (Invitrogen), named pLenti-ALPL. For downregulation ALPL, the shRNA sequences for targeting human ALPL were inserted in the pLko.1 vector (Invitrogen). The lentivirus contained with pLenti-ALPL or ALPL shRNA were produced by co-transfecting $293 \mathrm{~T}$ cells with the transfer lentiviral vector and two packaging vectors (psPAX2 and pMD2.G). The primers used to construct the lentiviral vectors of ALPL are listed in Supplementary Table 2.

\section{$\beta$-catenin siRNA transduction}

To silence $\beta$-catenin expression in HPP DSPCs, $\beta$ catenin siRNA (Ribobio, China) were transfected into HPP DSPCs at a final concentration of $50 \mathrm{nM}$ using riboFECT $^{\mathrm{ma}} \mathrm{CP}$ (Ribobio, China). NC siRNA was transfected as negative control. The silence efficiency on $\beta$ catenin was examined after transduction $48 \mathrm{~h}$ with $\beta$ catenin siRNA by RT-PCR and Western blotting.

\section{$\mathrm{LiCl}$ treatments in vitro}

A total of $1 \times 10 \mathrm{E} 5$ or $2 \times 10 \mathrm{E} 5$ DPSCs were plated in each well of 12-well or 6-well plates and cultured. After DPSCs reached above $90 \%$ confluence, the cells were cultured in odontoblastic differentiation medium containing $10 \mathrm{mM} \mathrm{LiCl}$ (Sigma, 213233) or $10 \mathrm{mM} \mathrm{NaCl}$, and the medium was changed three times per week. On days 7 and 21, the cells were harvested and performed with RC-PCR, Western blotting, and Alizarin Red staining as described above.

\section{$\mathrm{LiCl}$ intraperitoneal injection in vivo}

A total of 16 4-month-old ALPL ${ }^{+/-}$mice were randomly divided into $\mathrm{NaCl}$ group and $\mathrm{LiCl}$ group $(n=8$ per group). The $\mathrm{LiCl}$ group was injected $100 \mathrm{mg} / \mathrm{kg} \mathrm{LiCl}$ with body weight by intraperitoneal injection every other day for 4 weeks. The control mice received a comparable volume of $\mathrm{NaCl}$. All mice were sacrificed after injection 30 days for teeth analysis by micro-CT, immunofluorescent staining, H\&E, and SEM.

\section{Statistics}

The data were presented as the mean \pm s.d. All of the experiments were repeated more than three times. Statistical analysis was made using Student's $t$ test or one-way ANOVA, and the $p<0.05$ was considered significant.

\section{Results \\ Characteristics of the teeth from HPP patients and $\mathrm{ALPL}^{+/-}$mice}

HPP patients commonly face premature exfoliation teeth caused by dysplasia or aplasia of root or cementum [2, 23, 24]. We have collected two childhood HPP patients reported in our previous study [22]. Two patients displayed premature exfoliation of primary or permanent teeth. According to corresponding panoramic radiograph results, the height of the upper and lower jaws was insufficient, and the permanent dentition featured short roots and delayed eruption in HPP1(Fig. 1a). The alveolar bone height insufficient and short roots were observed in HPP2 (Fig. 1a). Fortunately, one lower cuspid from HPP1 was collected due to severe odontoseisis. The shape of pediatric deciduous cuspid is normal, with no root resorption, and rough root surface (Fig. 1b). Masson staining and H\&E staining showed that the 


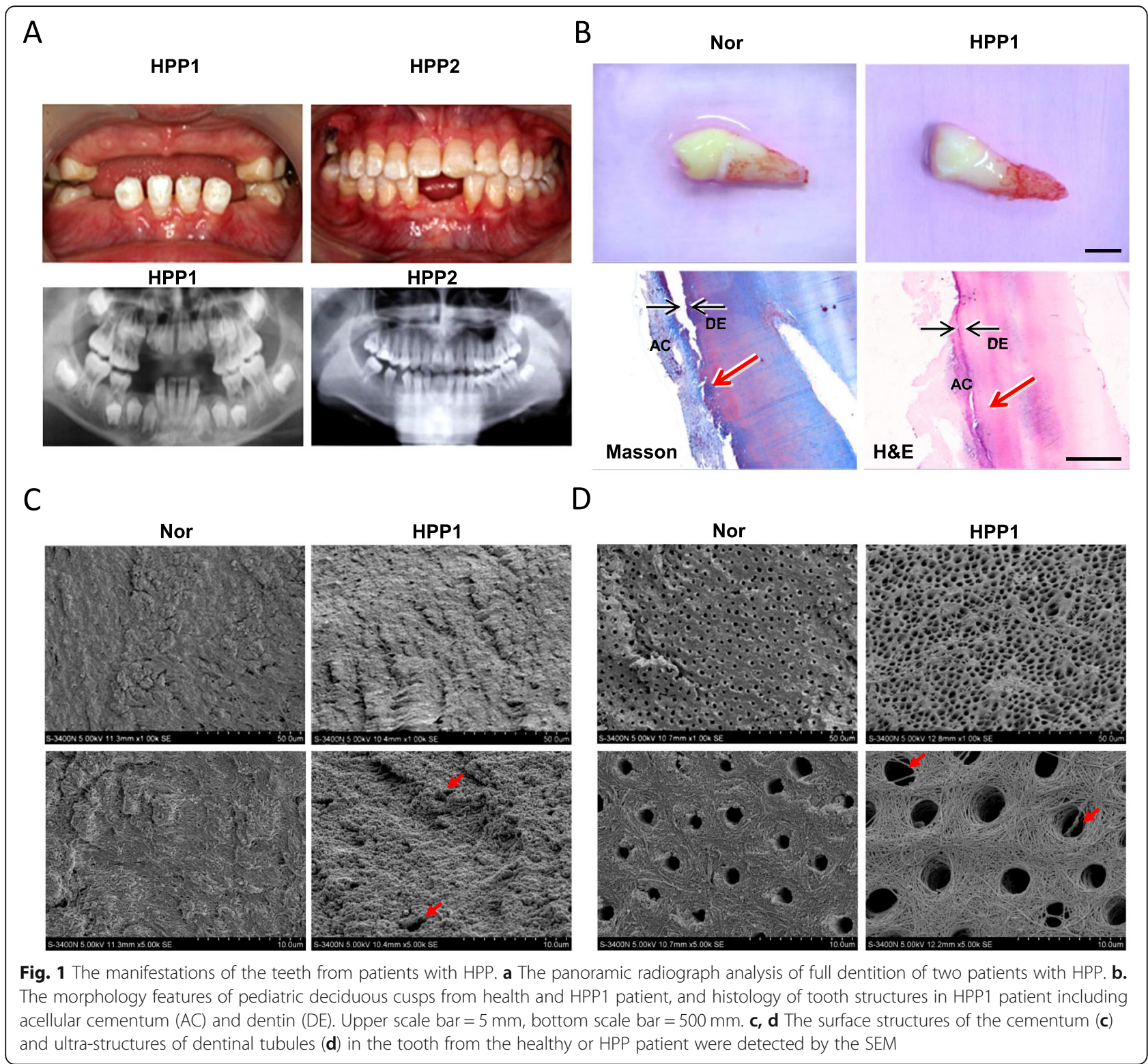

cementum layer was apparent thin and uneven surface. In addition, minority root was not covered with cementum, and cementum separated with dentin was observed (Fig. 1b). SEM results further showed that the surface of cementum in HPP1 patient were uneven and rough, and visible dentinal tubules open at root surface, while the surface of the cementum is smooth and homogenous in healthy tooth (Fig. 1c). The dentinal tubules in the HPP1 patient were irregular and low mineralized dentin and were larger lumen with obvious exposure of collagen fiber network than that in the normal deciduous tooth (Fig. 1d).

Previous studies have revealed that $\mathrm{ALPL}^{-1-}$ mice suffered severe insufficient mineralization of teeth and skeletal systems [25-27], and skeletal mineralization was significantly impaired in $\operatorname{ALPL}^{+/}$mice $[22,28]$. To investigate tooth defects in HPP, $\mathrm{ALPL}^{+/-}$mice were chosen as animal model, because of $\mathrm{ALPL}^{-/-}$ mice die from 14 to 21 days after birth [29]. First, we found the ALP activity in serum of ALPL knockdown mice reduced approximately $60 \%$ as compared with that of wild type mice (Fig. 2a). Next, to evaluate the effects of ALPL deficiency on the tooth, micro-CT analysis was performed. The results showed that the alveolar bone height, mandibular bone mass, and dentin mineral density (DMD) dramatically reduced in $\mathrm{ALPL}^{+/-}$mice compared with that in the control group (Fig. 2b). Moreover, ALPL knockdown 


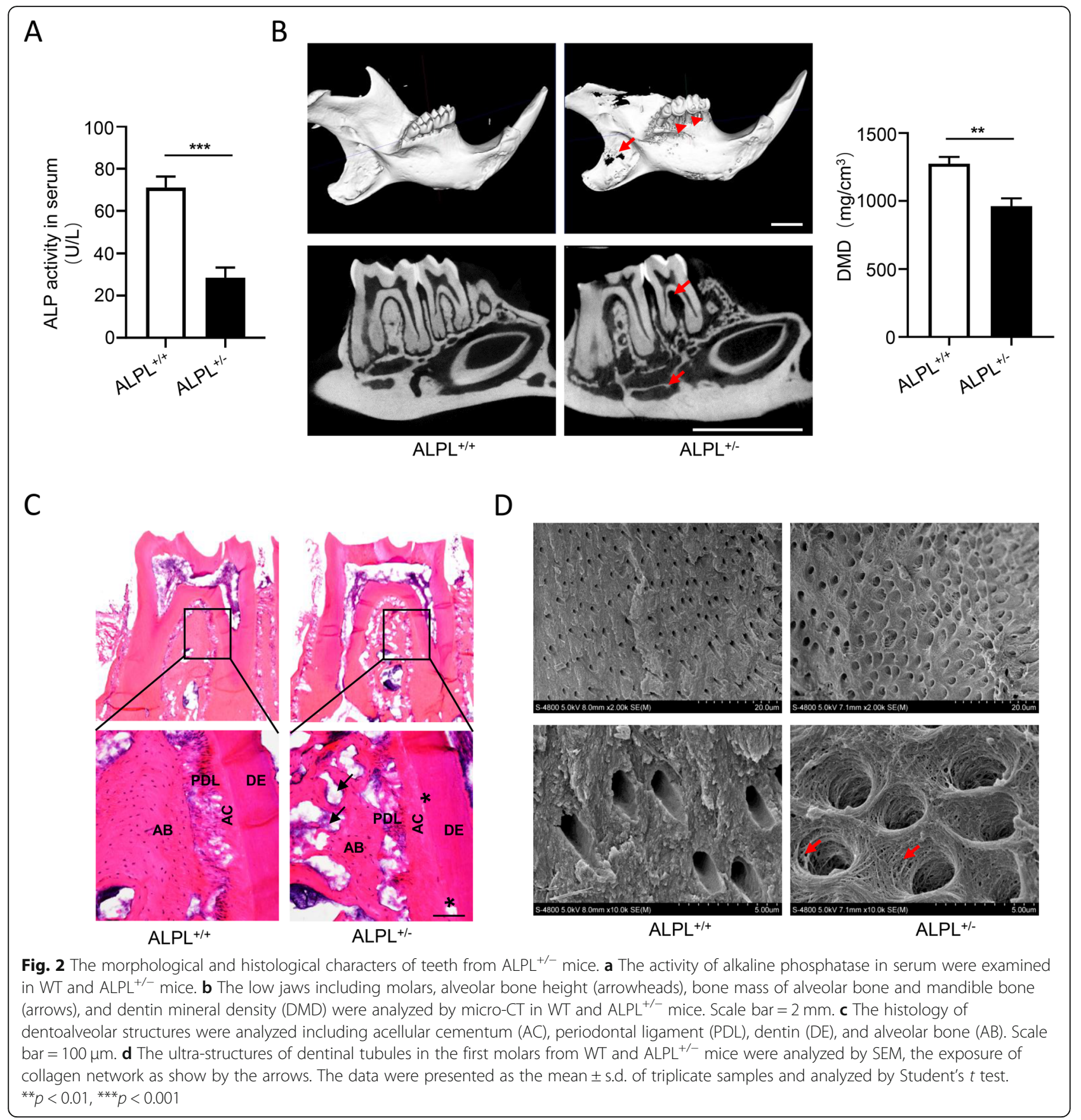

significantly decreased the alveolar bone mass and led to cementum partially segregated from dentin (Fig. $2 c, d)$. In addition, the dentinal tubules of the molars in $\mathrm{ALPL}^{+/-}$mice exhibited larger lumen with collagen fiber network exposure in contrast to the control group (Fig. 2d), which was observed in the HPP1 patient. Collectively, these results suggested $\mathrm{ALPL}^{+/-}$ mice exhibited tooth defects similar to HPPassociated periodontal disorder.
ALPL mutation impaired cell self-renewal and proliferation rather than cell apoptosis of DPSCs Increasing data provided the evidences that DPSCs cloud be induced to differentiate into odontoblasts and regenerate a dental pulp-dentin like tissue in vivo $[13,14]$. To further assess the role of ALPL in teeth development, DPSCs derived from HPP1 patient were isolated and cultured. First, we found that alkaline phosphatase activity and the protein expression of ALPL in HPP group 


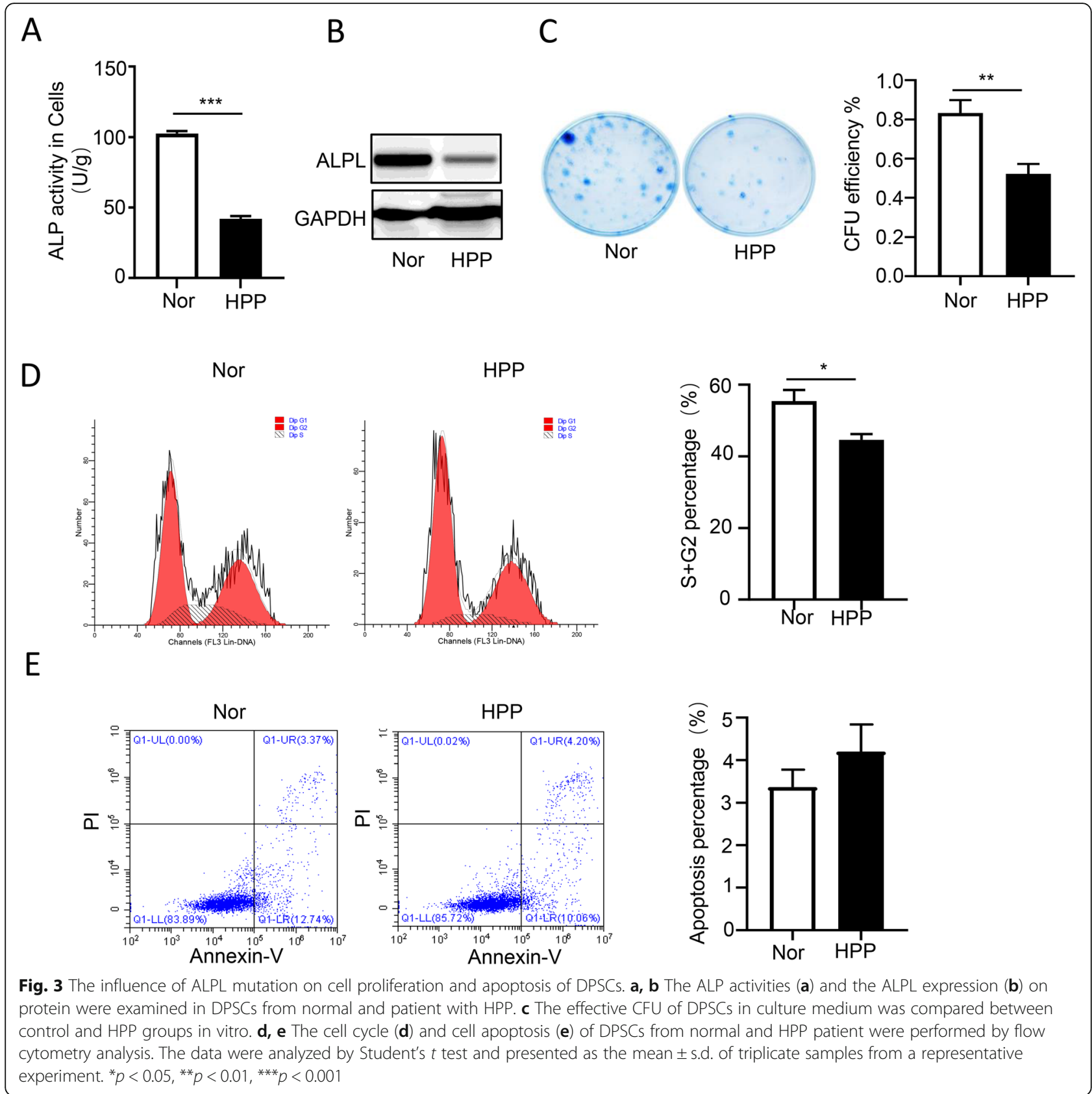

decreased significantly compared with that of the normal group (Fig. 3a). Then, to evaluate the roles of ALPL on cell self-renewal, cell proliferation, and apoptosis, the tests of colony formation, cell cycle, and cell apoptosis were performed. In contrast to normal DPSCs, the colony formation unit (CFU) efficiency significantly impaired (Fig. $3 \mathrm{~b}$ ) and the phage of $\mathrm{S}+\mathrm{G} 2$ in cell cycle (Fig. 3c) obviously reduced in HPP group, but the difference in cell apoptosis was not observed (Fig. 3d). Our results suggested that ALPL deficiency impaired cell selfrenewal and proliferation of DPSCs.
ALPL regulates the odontoblastic differentiation of DPSCs Given that impaired mineralization and exposure of collagen fiber network on dentinal tubules were observed both in HPP patient and $\mathrm{ALPL}^{+/-}$mice, we next evaluated the capacity of DPSCs from HPP differentiation into odontoblasts in vitro. The results of Alizarin Red staining showed that the potential odontoblastic differentiation capacity of HPP DPSCs significantly impaired (Fig. 4a), along with decreased expression of odontoblast-associated genes and proteins, DSPP and DMP1 (Fig. 4b). To further validate the role of ALPL in regulatory odontoblastic 


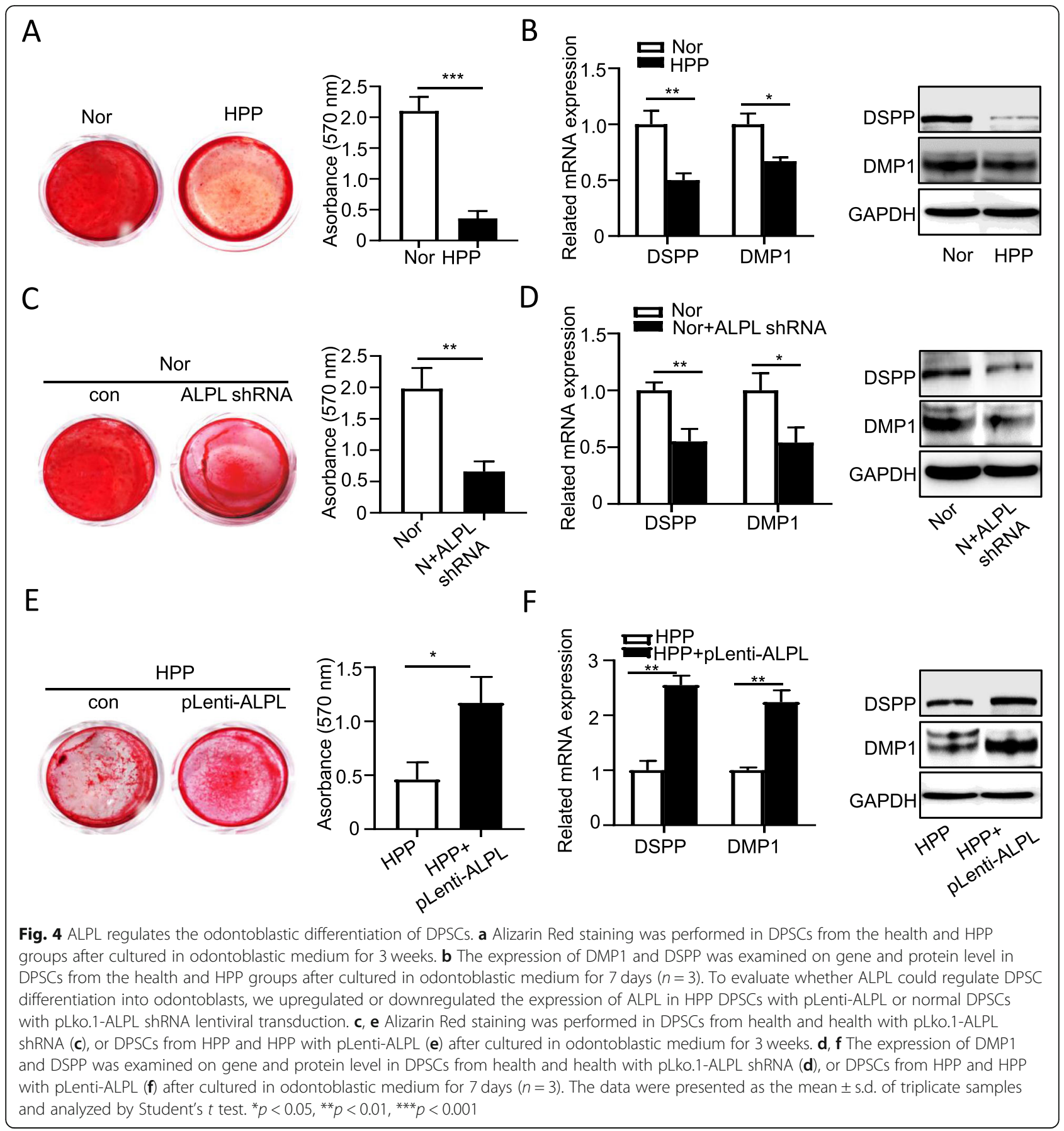

differentiation, we upregulated or downregulated the expression of ALPL in HPP DPSCs with plenti-ALPL lentivirus or normal DPSCs with plko.1-ALPL shRNA lentivirus (sFig. 2). The odontoblastic differentiation of normal DPSCs was inhibited by the downregulation of ALPL (Fig. 4c, d), mimicking the characteristic of HPP DPSCs, whereas recovery ALPL expression in HPP DPSCs remarkably promoted odontoblastic differentiation (Fig. 4e, f) as evidenced by Alizarin Red staining, and expressions of odontoblast associated genes and proteins.
Therefore, our results suggest that ALPL could be essential for DPSCs maintaining odontoblastic differentiation property.

ALPL regulates DPSC differentiation into odontoblasts by controlling canonical Wnt signaling pathway

Our previous study has demonstrated that ALPL deficiency-induced dysregulation of the phosphorylation of intracellular signaling proteins in MSCs [22]. We found that the protein levels of phosphorylation of 


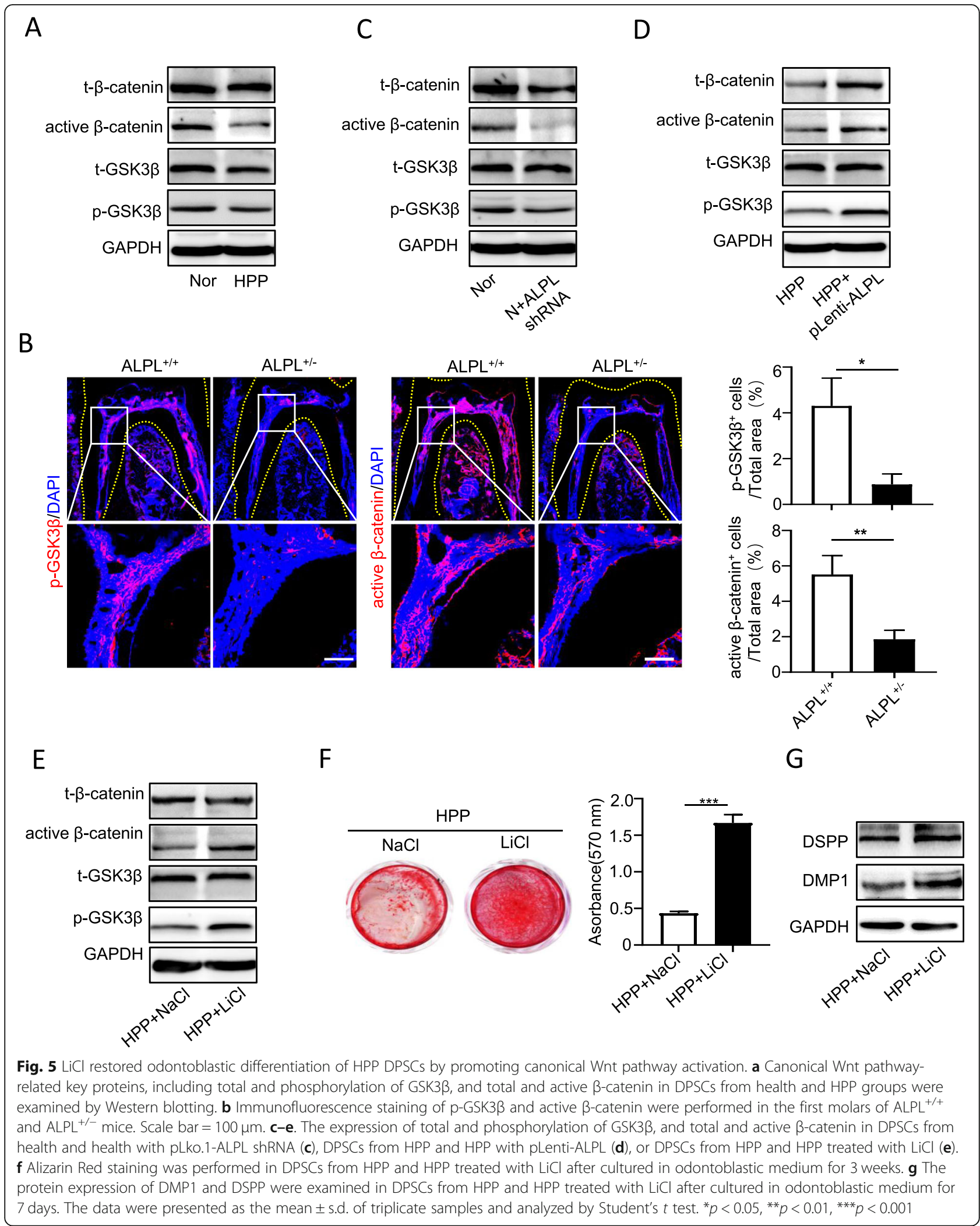


glycogen synthase kinase $3 \beta$ (p-GSK3 $\beta$ ), and active $\beta$ catenin in HPP DPSCs significantly decreased compared with that in healthy cells (Fig. 5a). In addition, Gli1 and phosphorylation of AMP-activated protein kinase $\alpha$ (AMPK $\alpha$ ) also decreased in HPP DPSCs, but not extracellular signal-regulated kinase1/2 (p-ERK1/2) (sFig. 3). Considering that GSK3 $\beta$-mediated canonical Wnt signaling pathway is a key signaling pathway for regulating tooth development $[30,31]$, the expression of p-GSK3 $\beta$ and active $\beta$-catenin in the first molars were examined by immunofluorescent staining. Notably, in contrast to the wild-type group, the expression of $\mathrm{p}-\mathrm{GSK} 3 \beta$ and active $\beta$-catenin significantly decreased especially in the dental pulp and alveolar bone in $\mathrm{ALPL}^{+/-}$mice as showed in immunofluorescence staining (Fig. 5b).

Then, to evaluate whether ALPL could regulate $\mathrm{p}$ GSK3 $\beta$ and active $\beta$-catenin expression, ALPL were downregulated in healthy DPSCs or upregulated in HPP DPSCs, respectively. The Western blotting results showed that downregulation of ALPL in normal cells significantly inhibited p-GSK3 $\beta$ and active $\beta$ catenin expression, while ALPL overexpression effectively promoted the expression of p-GSK3 $\beta$ and active $\beta$-catenin in HPP DPSCs (Fig. $5 \mathrm{c}, \mathrm{d}$ ). These results suggested that ALPL deficiency could disrupt canonical Wnt pathway activation and then impair DPSC differentiation into odontoblasts.

To resolve above question, the small molecule $\mathrm{LiCl}$, which is an agonist for high effective activating canonical Wnt signaling pathway by inhibited GSK3 $\beta$ activity [32, 33 ], were used to treat HPP DPSCs. As we expected, the expression of phosphorylation of GSK3 $\beta$ and active $\beta$ catenin increased dramatically in HPP DPSCs with $\mathrm{LiCl}$ treatment (Fig. 5e). Importantly, in contrast to the control group, the odontoblastic differentiation was prominently improved in HPP DPSCs after treated with $\mathrm{LiCl}$ by enhanced Alizarin Red staining and the protein expression of DSPP and DMP1 (Fig. 5f, g).

To further demonstrate that $\mathrm{LiCl}$ rescued the odontoblastic differentiation of HPP DPSCs by activating canonical Wnt pathway, these cells were treated with $\mathrm{LiCl}$ meanwhile interfered with $\beta$-catenin siRNA to block canonical Wnt pathway activation. The RT-PCR and Western blotting results showed that $\beta$-catenin siRNA strong silenced the expression of $\beta$-catenin in HPP DPSCs (Fig. 6a). Then, we found that the increased expression of active $\beta$-catenin, but not p-GSK3 $\beta$, in HPP DPSCs with $\mathrm{LiCl}$ treatment was inhibited by $\beta$-catenin siRNA (Fig. 6b). In addition, LiCl-improved odontoblastic differentiation of HPP DPSCs was almost blocked by silence $\beta$-catenin expression according to the results of Alizarin Red staining and Western blotting (Fig. 6c, d). Collectively, these results indicated that reactivated GSK3 $\beta$ to $\beta$-catenin signaling cascade cloud improve odontoblastic differentiation of HPP DPSCs.

\section{$\mathrm{LiCl}$ treatment ameliorates insufficient mineralization of dentin and mandible in $\mathrm{ALPL}^{+/-}$mice}

Next, to evaluate whether $\mathrm{LiCl}$ plays a therapeutic benefit on improving insufficient mineralization of the molars and mandible in ALPL knockout mice, the mice were administered $\mathrm{LiCl}$ every other day for 1 month. First, we observed the protein levels of p-GSK3 $\beta$ and active $\beta$ catenin increased significantly in the dental pulp and alveolar bone of $\mathrm{ALPL}^{+/-}$mice after $\mathrm{LiCl}$ treatment 1 month, compared with those in the $\mathrm{NaCl}$ group (Fig. 7a). Notably, micro-CT analysis confirmed that $\mathrm{ALPL}^{+/-}$ mice treated with $\mathrm{LiCl}$ displayed high alveolar bone height, increased bone mass of mandibular bone and alveolar bone, and DMD compared with those of the $\mathrm{NaCl}$ group (Fig. 7b). Further, the H\&E staining showed that $\mathrm{LiCl}$ injection increased the alveolar bone mass and improved segregation between dentin and cementum in ALPL knockdown mice (Fig. 7c). Meanwhile, the dentinal tubules with the larger lumen and collagen fiber network exposure in the molars of $\mathrm{ALPL}^{+/-}$mice were also ameliorated after $\mathrm{LiCl}$ treatment (Fig. $7 \mathrm{~d}$ ). In summary, our results provided the convincing proof for the mechanism that ALPL deficiency inhibited intracellular GSK3 $\beta$ to $\beta$-catenin signaling cascade leading to impairment of odontoblastic differentiation in DPSCs. While $\mathrm{LiCl}$ treatment could rescue such impairment through reactivating canonical Wnt pathway (Fig. 8).

\section{Discussion}

Tooth-associated defects, such as short roots with thin dentin, lack of acellular cementum, and alveolar bone loss, are the most common clinical manifestations of patients with HPP [1, 23, 24, 34, 35], and these phenotypes were also found in ALPL knockout mice or condition ALPL knockout mice [11, 27, 36]. However, the mechanism of dysplasia or aplasia of the teeth caused by loss of function of ALPL remains elusive. In this study, our goals were to evaluate the influence of ALPL mutation on bio-behaviors of DPSCs and reveal the potential mechanism on cellular signal transduction. Here, we provided the evidence that ALPL deficiency inhibited cell proliferation and odontoblastic differentiation of DPSCs from HPP patient. Furthermore, ALPL gene mutation caused GSK3 $\beta$ maintaining low phosphorylation status, and prevented $\beta$-catenin translocation into nucleus and inhibited activation of canonical Wnt signaling pathway, which is one of main signaling pathways for controlling lineage differentiation of MSCs [19, 37]. Notably, $\mathrm{LiCl}$ treatment reactivated intracellular GSK3 $\beta$ to $\beta$-catenin signaling cascade in DPSCs or dental pulp and restored impairment of odontoblastic differentiation, 


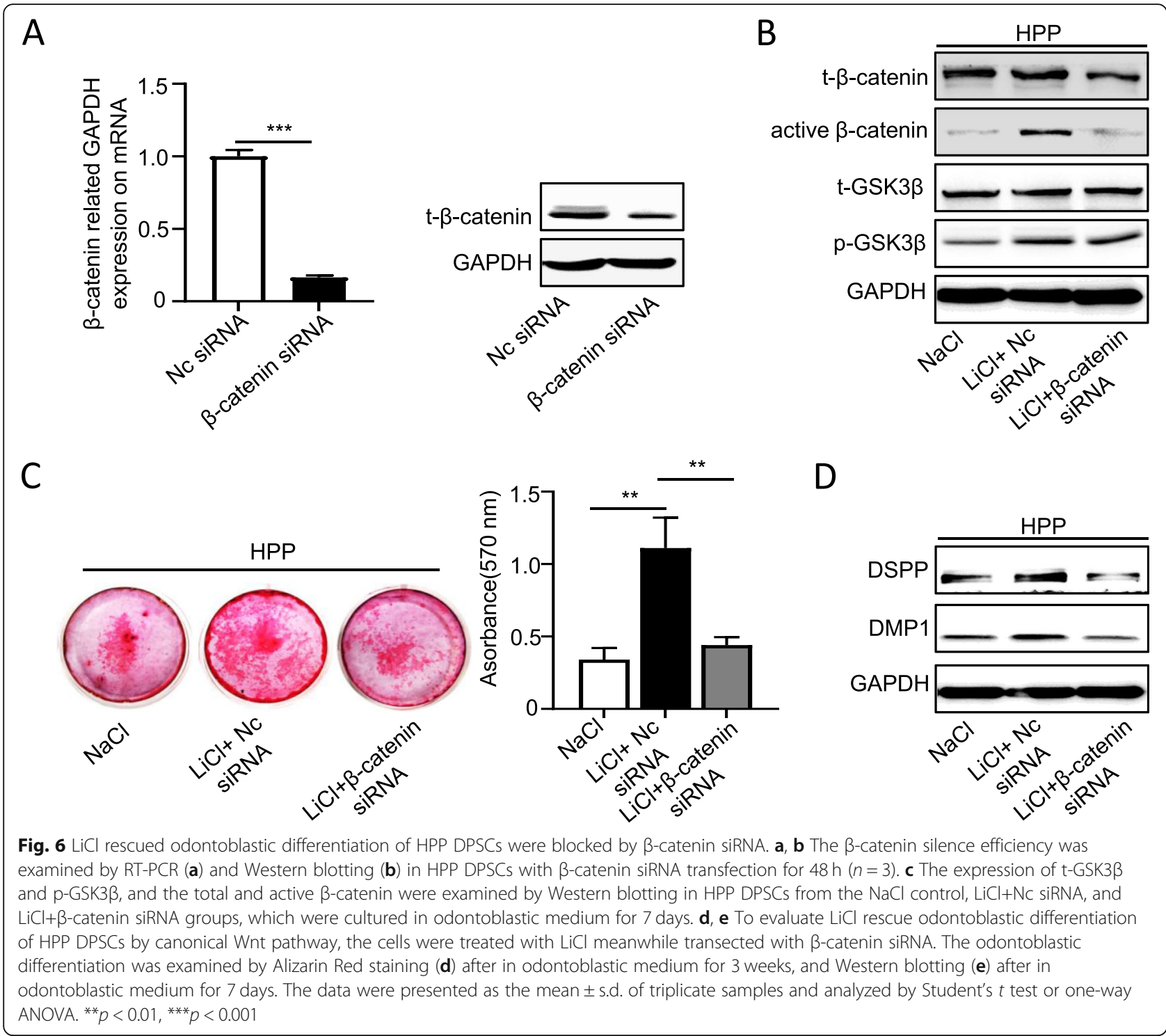

then ameliorated teeth and periodontal-related disorders in $\mathrm{ALPL}^{+/-}$mice.

Previous studies showed the accumulation of pyrophosphate (PPi), one of substrates of ALPL, in culture medium-impaired mineralization of dental pulp cells from HPP patients [17, 38]. However, researchers have not elucidated whether ALPL induces a series of intracellular changes. Here, we provided evidences that ALPL deficiency disrupted GSK3 $\beta$ to $\beta$-catenin signaling cascade and then inhibited expression of odontoblasticassociated genes, DMPP and DMP1, in DPSCs from HPP patient. Traditional knowledge indicates that ALPL is a downstream gene of canonical Wnt pathway [20, 39, 40] and plays main function on extracellular matrix mineralization of osteoblast, odontoblast, and ameloblast. Nevertheless, our results indicated that ALPL might be as a distinct regulator to control cellular signals cascade in MSCs. It may provide useful information for understanding ALPL mutations leading to tooth dysplasia.

Currently, enzyme replacement therapy with asfotase alfa was recognized as the only effective clinical treatment option for HPP. Increasing clinical data demonstrated that the most severe forms of HPP (prenatal and infantile) with asfotase alfa treatment significantly increased in bone mineral density and improved in respiratory and motor function [9, 41, 42]. One study recently reported about the dental status of HPP patients with asfotase alfa treatment. In their study, the author showed that enzyme replacement therapy significant decreased the mobility of the primary tooth in some cases [12], but a clinically defined improvement was also observed in some patients despite with long-term asfotase alfa treatment. The efficacy evaluation of the asfotase 


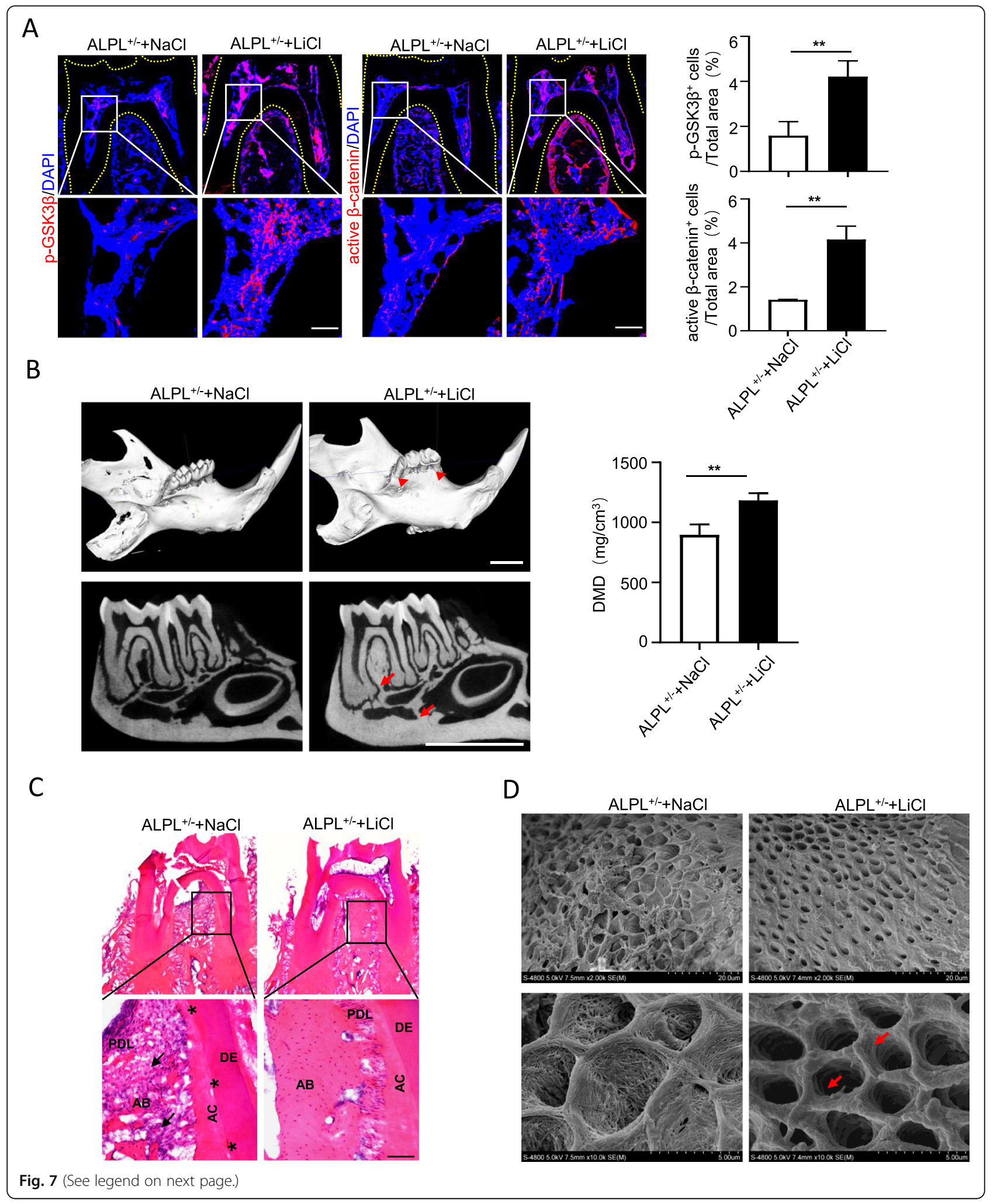


(See figure on previous page.)

Fig. 7 GSK3 $\beta$ rephosphorylation ameliorated tooth associated defects in $\mathrm{ALPL}^{+/-}$mice with LiCl treatment. a Immunofluorescence staining of $\mathrm{p}$ GSK3 $\beta$ and active $\beta$-catenin was performed in the first molars of $\mathrm{ALPL}^{+/-}$mice and $\mathrm{ALPL}^{+/-}$mice with $\mathrm{LiCl}$ treatment. Scale bar $=100 \mu \mathrm{m}$. $\mathbf{b}$ The micro-CT analysis of the low jaws including the molars, alveolar bone height (arrowheads), bone mass of alveolar bone and mandible bone (arrows), and DMD was performed in $\mathrm{ALPL}^{+-}$mice and $\mathrm{ALPL}^{+-}$mice treated with $\mathrm{LiCl}$. Scale bar $=2 \mathrm{~mm}$. c The histology of dentoalveolar structures including acellular cementum (AC), periodontal ligament (PDL), dentin (DE), and alveolar bone (AB) was analyzed in the first molars of $\mathrm{ALPL}^{+/-}$mice and $\mathrm{ALPL}^{+/-}$mice treated with $\mathrm{LiCl}$. Scale bar $=100 \mu \mathrm{m}$. d SEM analysis the ultra-structures of dentinal tubules in the first molars from $\mathrm{ALPL}^{+/-}$mice and $\mathrm{ALPL}^{+/-}$mice treated with $\mathrm{LiCl}$, and the dentinal tubules with exposure of collagen network of $\mathrm{ALPL}^{+/-}$mice were significantly improved after $\mathrm{LiCl}$ therapy as show by the arrows. $n=8$ mice per group. The data were presented as the mean \pm s.d. of triplicate samples and analyzed by Student's $t$ test. ${ }^{* *} p<0.01$

alfa on dental defects in HPP patients is very limited based on the current clinical data. Thus, prior to asfotase alfa therapy for dentist, the potential risks, effective treatment, and also expensive cost should be considered.

In the present study, we observed systemic $\mathrm{LiCl}$ injections effectively improved mineralization of dentinal tubules, but also increased height and bone mass of alveolar bone, and DMD in ALPL knockdown mice. We could not exclude whether other types of cells in periodontal tissues were also affected by systemic $\mathrm{LiCl}$ injections. Indeed, periodontal ligament stem cells derived from tooth and BMSCs from the jaw are also important for the tooth development and functional maintenance [43]. Despite that our previous works demonstrated $\mathrm{LiCl}$
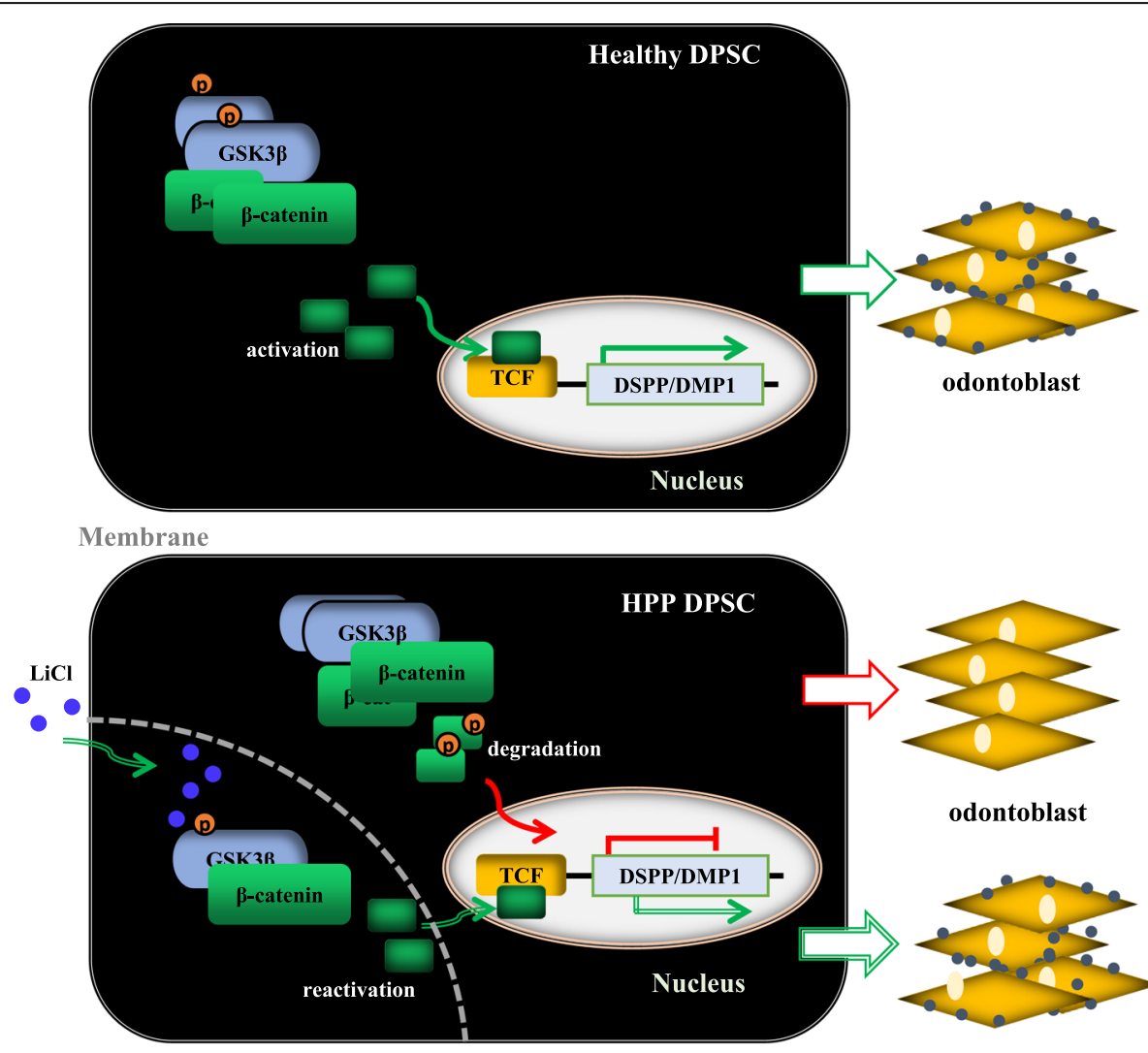

odontoblast
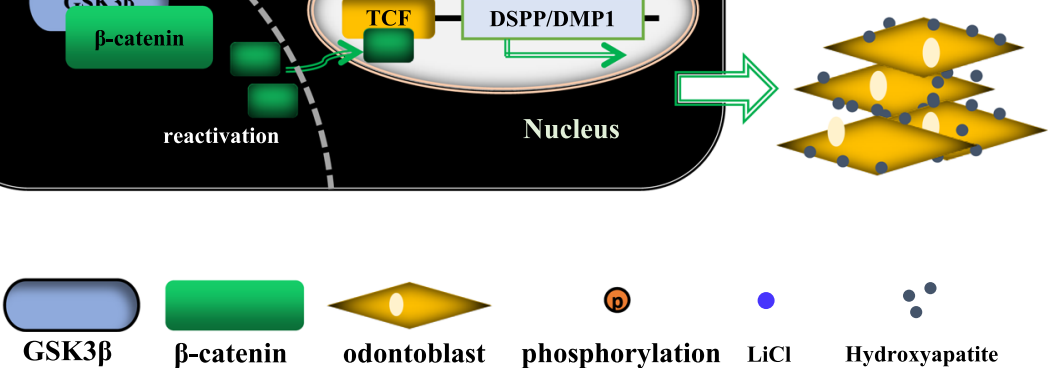

(D)

phosphorylation LiCl

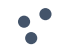

Hydroxyapatite

Fig. 8 Schematic diagram depicts how ALPL deficiency impairs DPSC differentiation into odontoblasts and a therapeutic method. In Healthy DPSC, ALPL is essential for regulating canonical Wnt signal pathway activation, which increases the expression of odontoblast-associated gene, DSPP and DMP1, and subsequently promotes odontoblastic differentiation of DPSC. In HPP DPSC, ALPL deficiency caused by ALPL mutation, disrupted intracellular GSK3 $\beta$ to $\beta$-catenin signaling cascade, then impaired odontoblastic differentiation of DPSC. While LiCI treatment can rescue the impairment of odontoblastic differentiation of HPP DPSC through reactivating intracellular GSK3 $\beta$ to $\beta$-catenin signaling transduction 
treatment improved bone mass loss of femora, it might explain why systemic $\mathrm{LiCl}$ injections also increased bone mass of the alveolar bone in $\mathrm{ALPL}^{+/-}$mice. It still needs to be evaluated whether ALPL deficiency disrupts GSK3 $\beta / \beta$-catenin cascade, and $\mathrm{LiCl}$ exerts therapeutic benefits in these cells. Therefore, it urgently needs to evaluate $\mathrm{LiCl}$ therapeutic benefits in dental stem cells and tooth defects in ALPL knockdown mice and the regulatory relationship between ALPL and GSK3 $\beta$ in the following works, and ultimately, these works may inform efforts at improvement tooth defects in HPP patients.

\section{Conclusions}

Here, our study indicated that ALPL might be as a distinct regulator to control intracellular GSK3 $\beta$ to $\beta$ catenin signals cascade and subsequently regulate DPSC differentiation into odontoblast. ALPL deficiency impaired odontoblastic differentiation of DPSCs, while $\mathrm{LiCl}$ treatment could rescue such impairment through rephosphorylation of GSK3 $\beta$. This work may provide useful information for understanding how ALPL mutations leading to tooth dysplasia and, ultimately, may inform efforts at improvement tooth defects in patients with HPP.

\section{Abbreviation \\ ALPL: Liver/bone/kidney-type alkaline phosphatase; HPP: Hypophosphatasia; DPSC: Dental pulp stem cells; t-GSK3 $\beta$ : Total glycogen synthase kinase 3; DSPP: Dentin sialophosphoprotein; DMP1: Dentin matrix acidic phosphoprotein 1; p-GSK3 3 : Phosphorylation of glycogen synthase kinase 3 beta; micro-CT: Micro-computed tomography; RT-PCR: Real-time polymerase chain reaction}

\section{Supplementary Information}

The online version contains supplementary material available at https://doi. org/10.1186/s13287-021-02235-7.

Additional file 1: sFig. 1 identification of DPSCs phenotype by flow cytometer. The makers of DPSCs, including CD29, CD44, CD105, CD34, CD45, and Stro-1, were examined by flow cytometric cytometer in health and patient with HPP.

Additional file 2: sFig. 2 The silence and overexpression efficiency of ALPL. a The expression of ALPL protein were examined by western blotting in health DPSCs and health DPSCs with pLko.1-ALPL shRNA lentiviral transduction for $48 \mathrm{~h}$. b The expression of ALPL protein were examined by western blotting in HPP DPSCs and HPP DPSCs with pLentiALPL lentiviral transduction for $48 \mathrm{~h}$.

Additional file 3: sFig. 3 The expression of signaling proteins in DPSCs. The expression of signaling proteins, including p-ERK, p-AMPK, Gli1, and TGF $\beta$, were examined by western blotting in DPSCs from health and HPP groups.

Additional file 4: Supplementary Table 2. Primers sequences used to construct the ALPL lentiviral vectors. Supplementary Table 1. Primers sequences for Real-Time PCR assay.

\section{Acknowledgements}

We great thank Professor Yan Jin for the intellectual suggestions and help on this work.

\section{Authors' contributions}

Wenjia Liu and Kun Xuan designed the project. Liqiang Zhang and Jiangdong Zhao did the majority of the experiments and collected data. Jiayi Dong did the experiment of microCT and collected data. Yuting Liu participated in the experiments and collected data. Liqiang Zhang drafted the manuscript. The authors contributed to and approved the final version of the manuscript

\section{Funding}

This work was supported by the International Cooperation and Exchanges NSFC (81620108007), National Key Research and Development Program of China (2017YFA0104800), National Natural Science Foundation of China (81870796 and 81970915), and Natural Science Fund of Shaanxi for distinguished Young Scholars (2020JC33).

\section{Availability of data and materials}

All datasets used and/or analyzed during the current study are available from the corresponding author on reasonable request.

\section{Declarations}

Ethics approval and consent to participate

Mice were used according to federal guidelines and as approved by the Animal Ethical and Welfare Committee of Xi'an Jiaotong University (No. XJTULAC201).

\section{Consent for publication}

Not applicable.

\section{Competing interests}

All the authors declare no conflict of interest.

\section{Author details}

${ }^{1}$ National \& Local Joint Engineering Research Center of Biodiagnosis and Biotherapy, Precision Medicine Institute, The Second Affiliated Hospital of Xi'an Jiaotong University, No.157 Xiwu Road, Xi'an 710004, China. ${ }^{2}$ Xi'an Institute of Tissue Engineering and Regenerative Medicine, Xi'an 710032, Shaanxi, China. ${ }^{3}$ The Key Laboratory of Aerospace Medicine, Ministry of Education, Air Force Medical University, Xi'an 710032, Shaanxi, China. ${ }^{4}$ State Key Laboratory of Military Stomatology \& National Clinical Research Center for Oral Diseases \& Shaanxi International Joint Research Center for Oral Diseases, Center for Tissue Engineering, School of Stomatology, The Fourth Military Medical University, No. 145 West Changle Road, Xi'an 710032, Shaanxi, China. ${ }^{5}$ Department of Pediatric Dentistry, School of Stomatology, Fourth Military Medical University, Xi'an, China.

Received: 3 December 2020 Accepted: 21 February 2021

Published online: 06 April 2021

\section{References}

1. Beumer J 3rd, Trowbridge HO, Silverman S Jr, Eisenberg E. Childhood hypophosphatasia and the premature loss of teeth. Oral Surg Oral Med Oral Pathol. 1973;35:631-40.

2. Haliloglu B, Guran T, Atay Z, Abali S, Mornet E, Bereket A, et al. Infantile loss of teeth: odontohypophosphatasia or childhood hypophosphatasia. Eur J Pediatr. 2013;172:851-3.

3. Simon S, Resch H, Klaushofer K, Roschger P, Zwerina J, Kocijan R. Hypophosphatasia: from diagnosis to treatment. Curr Rheumatol Rep. 2018; 20:69.

4. Rush ET. Childhood hypophosphatasia: to treat or not to treat. Orphanet J Rare Dis. 2018;13:116.

5. Whyte MP. Hypophosphatasia: enzyme replacement therapy brings new opportunities and new challenges. J Bone Miner Res. 2017;32:667-75.

6. Whyte MP, Greenberg CR, Salman NJ, Bober MB, McAlister WH, Wenkert D, et al. Enzyme-replacement therapy in life-threatening hypophosphatasia. N Engl J Med. 2012;366:904-13.

7. Costain G, Moore AM, Munroe L, Williams A, Zlotnik Shaul R, RockmanGreenberg C, et al. Enzyme replacement therapy in perinatal hypophosphatasia: case report of a negative outcome and lessons for clinical practice. Mol Genet Metab Rep. 2018;14:22-6. 
8. Scott LJ. Asfotase alfa in perinatal/infantile-onset and juvenile-onset hypophosphatasia: a guide to its use in the USA. BioDrugs. 2016;30:41-8.

9. Whyte MP, Simmons JH, Moseley S, Fujita KP, Bishop N, Salman NJ, et al. Asfotase alfa for infants and young children with hypophosphatasia: 7 year outcomes of a single-arm, open-label, phase 2 extension trial. Lancet Diabetes Endocrinol. 2019;7:93-105.

10. Cheung WS. A mild form of hypophosphatasia as a cause of premature exfoliation of primary teeth: report of two cases. Pediatr Dent. 1987;9:49-52.

11. Foster BL, Kuss P, Yadav MC, Kolli TN, Narisawa S, Lukashova L, et al. Conditional Alpl ablation phenocopies dental defects of hypophosphatasia. J Dent Res. 2017:96:81-91.

12. Kiselnikova L, Vislobokova E, Voinova V. Dental manifestations of hypophosphatasia in children and the effects of enzyme replacement therapy on dental status: a series of clinical cases. Clin Case Rep. 2020;89: 11-18.

13. Miura M, Gronthos S, Zhao M, Lu B, Fisher LW, Robey PG, et al. SHED: stem cells from human exfoliated deciduous teeth. Proc Natl Acad Sci U S A. 2003;100:5807-12.

14. Cordeiro MM, Dong Z, Kaneko T, Zhang Z, Miyazawa M, Shi S, et al. Dental pulp tissue engineering with stem cells from exfoliated deciduous teeth. J Endod. 2008;34:962-9.

15. Huang GT, Yamaza T, Shea LD, Djouad F, Kuhn NZ, Tuan RS, et al. Stem/ progenitor cell-mediated de novo regeneration of dental pulp with newly deposited continuous layer of dentin in an in vivo model. Tissue Eng Part A. 2010;16:605-15.

16. Xuan K, Li B, Guo H, Sun W, Kou X, He X, et al. Deciduous autologous tooth stem cells regenerate dental pulp after implantation into injured teeth. Sci Transl Med. 2018;10:eaaf3227.

17. Liu H, Li J, Lei H, Zhu T, Gan Y, Ge L. Genetic etiology and dental pulp cell deficiency of hypophosphatasia. J Dent Res. 2010;89:1373-7.

18. Rodrigues TL, Fau FB, Silverio KG, Fau SK, Martins L, Fau ML, Casati MZ, Fau CM, Sallum EA, Fau SE, Somerman MJ, et al. Hypophosphatasia-associated deficiencies in mineralization and gene expression in cultured dental pulp cells obtained from human teeth. J Endod. 2012;38:902-12.

19. Visweswaran M, Pohl S, Arfuso F, Newsholme P, Dilley R, Pervaiz S, et al. Multi-lineage differentiation of mesenchymal stem cells - to Wnt, or not Wnt. Int J Biochem Cell Biol. 2015;68:139-47.

20. Heo JS, Lee SY, Lee JC. Wnt/beta-catenin signaling enhances osteoblastogenic differentiation from human periodontal ligament fibroblasts. Mol Cells. 2010:30:449-54.

21. Zhang $X$, Ning T, Wang $H, X u S, Y u H$, Luo $X$, et al. Stathmin regulates the proliferation and odontoblastic/osteogenic differentiation of human dental pulp stem cells through Wnt/beta-catenin signaling pathway. J Proteome. 2019;202:103364.

22. Liu W, Zhang L, Xuan K, Hu C, Li L, Zhang Y, et al. Alkaline phosphatase controls lineage switching of mesenchymal stem cells by regulating the LRP6/GSK3beta complex in hypophosphatasia. Theranostics. 2018;8:5575-92.

23. Bruckner RJ, Rickles NH, Porter DR. Hypophosphatasia with premature shedding of teeth and aplasia of cementum. Oral Surg Oral Med Oral Pathol. 1962;15:1351-69.

24. Mussolino Ribeiro ZM, Assed S, Borsatto MC, Campos de Freitas A Hypophosphatasia--premature loss of deciduous teeth. Rev Fac Odontol Ribeiro Preto. 1986;23:107-14

25. Oikawa H, Tomatsu S, Haupt B, Montano AM, Shimada T, Sly WS. Enzyme replacement therapy on hypophosphatasia mouse model. J Inherit Metab Dis. 2014;37:309-17.

26. Millan JL, Narisawa S, Lemire I, Loisel TP, Boileau G, Leonard P, et al. Enzyme replacement therapy for murine hypophosphatasia. J Bone Miner Res. 2008; 23:777-87.

27. Gasque KC, Foster BL, Kuss P, Yadav MC, Liu J, Kiffer-Moreira T, et al. Improvement of the skeletal and dental hypophosphatasia phenotype in Alpl-/- mice by administration of soluble (non-targeted) chimeric alkaline phosphatase. Bone. 2015:72:137-47.

28. Liu W, Zhang L, Xuan K, Hu C, Liu S, Liao L, et al. Alpl prevents bone ageing sensitivity by specifically regulating senescence and differentiation in mesenchymal stem cells. Bone Res. 2018:6:27.

29. Waymire KG, Fau MJ, Jaje JM, Fau JJ, Guilarte TR, Fau GT, Coburn SP, Fau CS, GR MG, GR MG. Mice lacking tissue non-specific alkaline phosphatase die from seizures due to defective metabolism of vitamin B-6. Nat Genet. 1995; $11: 45-51$.
30. Song Y, Liu X, Feng X, Gu Z, Gu Y, Lian M, et al. NRP1 accelerates odontoblast differentiation of dental pulp stem cells through classical Wnt/ beta-catenin signaling. Cell Reprogram. 2017;19:324-30.

31. Wang C, Song Y, Gu Z, Lian M, Huang D, Lu X, et al. Wedelolactone enhances odontoblast differentiation by promoting Wnt/beta-catenin signaling pathway and suppressing NF-kappaB signaling pathway. Cell Reprogram. 2018;20:236-44.

32. Hao HP, Wen LB, Li JR, Wang Y, Ni B, Wang R, et al. LiCl inhibits PRRSV infection by enhancing Wnt/beta-catenin pathway and suppressing inflammatory responses. Antiviral Res. 2015;117:99-109.

33. Li C, Zhang Y, Lu Y, Cui Z, Yu M, Zhang S, et al. Evidence of the cross talk between Wnt and Notch signaling pathways in non-small-cell lung cancer (NSCLC): Notch3-siRNA weakens the effect of $\mathrm{LiCl}$ on the cell cycle of NSCL C cell lines. J Cancer Res Clin Oncol. 2011;137:771-8.

34. el-Labban NG, Lee KW, Rule D. Permanent teeth in hypophosphatasia: light and electron microscopic study. J Oral Pathol Med. 1991;20:352-60.

35. Hayashi-Sakai S, Numa-Kinjoh N, Sakamoto M, Sakai J, Matsuyama J, Mitomi T, et al. Hypophosphatasia: evaluation of size and mineral density of exfoliated teeth. J Clin Pediatr Dent. 2016;40:496-502.

36. Ikeue R, Nakamura-Takahashi A, Nitahara-Kasahara Y, Watanabe A, Muramatsu T, Sato T, et al. Bone-targeted alkaline phosphatase treatment of mandibular bone and teeth in lethal hypophosphatasia via an scAAV8 vector. Mol Ther Methods Clin Dev. 2018;10:361-70.

37. James AW. Review of signaling pathways governing MSC osteogenic and adipogenic differentiation. Scientifica (Cairo). 2013;2013:684736.

38. Rodrigues TL, Foster BL, Silverio KG, Martins L, Casati MZ, Sallum EA, et al. Hypophosphatasia-associated deficiencies in mineralization and gene expression in cultured dental pulp cells obtained from human teeth. J Endod. 2012;38:907-12.

39. Morsczeck C, Reck A, Reichert TE. WNT3A and the induction of the osteogenic differentiation in adipose tissue derived mesenchymal stem cells. Tissue Cell. 2017:49:489-94.

40. Rawadi G, Vayssiere B, Dunn F, Baron R, Roman-Roman S. BMP-2 controls alkaline phosphatase expression and osteoblast mineralization by a Wnt autocrine loop. J Bone Miner Res. 2003:18:1842-53.

41. Hofmann C, Seefried L, Jakob F. Asfotase alfa: enzyme replacement for the treatment of bone disease in hypophosphatasia. Drugs Today (Barc). 2016 52:271-85.

42. Whyte MP, Rockman-Greenberg C, Ozono K, Riese R, Moseley S, Melian A, et al. Asfotase alfa treatment improves survival for perinatal and infantile hypophosphatasia. J Clin Endocrinol Metab. 2016;101:334-42.

43. Dave JR, Tomar GB. Dental tissue-derived mesenchymal stem cells: applications in tissue engineering. Crit Rev Biomed Eng. 2018;46:429-68.

\section{Publisher's Note}

Springer Nature remains neutral with regard to jurisdictional claims in published maps and institutional affiliations.

Ready to submit your research? Choose BMC and benefit from:

- fast, convenient online submission

- thorough peer review by experienced researchers in your field

- rapid publication on acceptance

- support for research data, including large and complex data types

- gold Open Access which fosters wider collaboration and increased citations

- maximum visibility for your research: over $100 \mathrm{M}$ website views per year

At $\mathrm{BMC}$, research is always in progress.

Learn more biomedcentral.com/submission 